\title{
PERMAINAN MONOPOLI BERBASIS METODE STAD (STUDENT TEAMS ACHIEVEMENT DIVISION) SEBAGAI MEDIA PEMBELAJARAN BIOLOGI MATERI SISTEM PENCERNAAN
}

\author{
Ika Suci Rahayu \\ Handoko Santoso ${ }^{2}$ \\ Triana Asih ${ }^{3}$ \\ 1,2,3 Pendidikan Biologi FKIP, Universitas Muhammadiyah Metro \\ E-mail: ${ }^{1}$ ikasucirahayu18@gmail.com, ${ }^{2}$ handoko.umm@gmail.com, ${ }^{3}$ asih.triana@yahoo.com
}

\section{History Article \\ Received: 1 Oktober 2019 Approved: 1 November 2019 Published: 1 Desember 2019}

\section{Keywords: $\quad$ STAD} method, monopoly game, human digestive system

\begin{abstract}
Learning media is an intermediary used for student learning tools. Students in the learning process feel bored with the delivery of material. Submission of material that is less varied causes students to be less active so that the understanding of the material is not optimal. The teacher uses torso media in learning but the learning outcomes are still less than KKM (Minimum completeness criteria). One way to overcome this is by developing monopoly games as biology learning media. Monopoly game is a type of board game that aims to accumulate wealth and control complexes on a monopoly board game. The teacher can modify the shape of this monopoly board game (astuti: 2014). The use of instructional media appropriately and varied can overcome the passive attitudes of students and overcome boredom during the learning process. Monopoly Game Development as a Biology Learning Media Material of Digestive System Based on STAD (Student Teams Achievement Division) Method is interesting to be studied.The purpose of this research is to produce a media product in the form of a decent monopoly game for learning biology of the human digestive system. This type of research is the development of the $4 D$ model (Define, Design, Develop, Desseminat or $4 P$ called defining, planning, developing and disseminating. Monopoly Game Development as a Biological Learning Media for Digestive System Material using the STAD (Student Teams Achievement Division) method. Media development was validated by biology lecturers and subject teachers as media design experts and the material was subsequently tested on grade XI students.The results of recapitulation of expert validation and student trials showed very good criteria, namely: (a) Aspects of media design reached an average score of $88.7 \%$ (b) Aspects of material reached an average score of $89.1 \%$ and (c) trials learners reach a score of $90.25 \%$. This study can be concluded that the Monopoly Game as a Learning Media for Biology of the Digestive System Material Based on the STAD Method (Student Teams Achievement Division) is suitable for the learning process facilities.
\end{abstract}

\section{How to Cite}

Rahayu, I. S., Santoso, H., Asih, T. 2019. Permainan Monopoli Berbasis Metode Stad (Student Teams Achievement Division) Sebagai Media Pembelajaran Biologi Materi Sistem Pencernaan. Edubiolock, 1(1), $1-7$. 


\section{RAHAYU, I. S., SANTOSO, H., ASIH, T. 2019. Permainan Monopoli...}

\section{PENDAHULUAN}

Media pembelajaran adalah suatu perantara yang digunakan untuk sarana belajar siswa. Berdasar pra-survei yang telah dilakukan di SMA Negeri 1 Punggur pada 16 November 2017 dengan guru pengampu mata pelajaran biologi diperoleh data wawancara yaitu siswa dalam proses pembelajaran sering merasa bosan dengan cara penyampaian materi. Penyampaian materi yang kurang variatif mengakibatkan siswa cenderung tidak aktif sehingga dalam pemahaman materi tidakoptimal. Guru menggunakan media torso yang mana terdiri dari bagian organ-organ pencernaan namunhasil belajar kurang mecapai KKM (Kriteria Kelulusan Minimal).Salah satu cara mengatasi hal demikian yakni dengan mengembangkan permainan monopoli sebagai media pembelajaran biologi. Sejarah permainan monopoli adalah salah satu jenis permainan papan yang bertujuan untuk mengumpulkan kekayaan dan menguasai komplek-komplek pada papan permainan monopoli. Guru dapat memodifikasi bentuk papan permainan monopoli ini (Astuti, 2014). Penggunaan media pembelajaran secara tepat dan bervariasi dapat mengatasi sikap pasif anak didik dan mengatasi rasa bosan saat proses pembelajaran. Salah satu macam metodecooperative learning yaitu metode STAD (Student Teams Achievement Division), model ini dijabarkan oleh Robert Slavin. Metode STAD merupakan variasi pembelajaran kooperatif. Metode ini juga dapat diadaptasi dalam matematika, IPA, IPS, bahasa inggris, teknik dari tingkat sekolah dasar hingga perguruan tinggi. Pengembangan media monopoli ini penggunaannya dengan metode STAD (Student Teams Achievement Division) bertujuan untuk meningkatkan aktifitas dan interaksi di antara peserta didikjuga interaksi guru dengan peserta didik. Peserta didik dapat belajar dengan aktif dan tidak merasa bosan karena belajar dengan permainan, untuk saling memotivasi dan saling membantu antar peserta didik dalam menguasai materi pelajaran guna mencapai prestasi yang maksimal. Pengembangan Permainan Monopoli Sebagai Media Pembelajaran Biologi Materi Sistem Pencernaan Berbasis Metode STAD (Student Teams Achievement Division) dirasa dapat mengatasi masalah tersebut.

Berdasarkan rumusan masalah tujuan penelitian yang ingin dicapai dalam proyek pengembangan ini yaitu untuk menghasilkan produk Media Pembelajaran Biologi Berupa Permainan Monopoli yang layak untuk Pembelajaran Biologi Materi Sistem Pencernaan kelas IX yang penggunaanya berbasis Metode STAD (Student Teams Achievement Division).

Menurut Duludu (2017) menyatakan bahwa media pembelajaran yaitu: suatu perantara yang digunakan oleh pendidik/guru untuk menyalurkan pesan atau informasi kepada siswanya sehingga siswa tersebut dapat terangsang ketika mengikuti kegiatan pembelajaran. Dapat dikatakan pula media pembelajaran dapat memudahkan siswa untuk menerima pembelajaran yang disampaikan pendidik/guru. Sadiman (2006) menyatakan bahwamedia grafis merupakan media visual. Seperti lainnya media yang lain media grafis berfungsi untuk menyampaikan pesan dari sumber ke penerima pesan. Saluran yang dipakai menggunakan indra penglihatan. Beberapa contoh media grafis yaitu foto alat perekam pita, video dan permainan atau simulasi.Menurut astuti (2014) permainan monopoli merupakan salah satu jenis permainan papan yang bertujuan untuk mengumpulkan kekayaan dan menguasai komplek-komplek pada papan permainan monopoli. Guru dapat memodifikasi bentuk papan permainan monopoli ini serta dengan segala peraturannya agar dapat digunakan sebagai media pembelajaran. Menurut Taufiq (2016) menyatakan bahwa model 
pembelajaran STAD menekankan pembelajaran secara langsung dan model yang mudah diaplikasikan pada mata pelajaran ipa salah satunya mata pelajaran biologi, model pembelajarannya ini sistemnya yakni menekankan tanggungjawab kepada timnya dan tanggungjawab dirinya agar bisa menjawab soal dan bisa meraih skor tertinggi.Penerapan model pembelajaran Cooperative Learning Tipe STAD perlu didukung oleh media yang dapat mendukung aktivitas belajar siswa agar lebih semangat dalam belajar.

\section{METODE}

Metode pengembangan yang akan digunakan dalam penelitain ini adalah model pengembangan Tiagarajan yaitu model pengembangan 4 (Four) D. TahapTahap model pengembangan $4 \mathrm{D}$ ada 4 tahap yaitu Define, Desain, Develop, dan Desseminate yang diaplikasikan menjadi 4 $\mathrm{P}$ yakni pendefinisian, perancangan, pengembangan dan penyebaran. Langkahlangkah pengembangan $4 \mathrm{D}$ yaitu:

\section{Tahap Pendefinisian (Define)}

Tahap ini peneliti melaksanakan wawancara terhadap guru SMA N 1 Punggur untuk mengetahui masalahmasalah yang terjadi di sekolah khususnya pada perangkat pembelajaran yang mana terdiri dari analisis ujung depan dan analisis materi. Tahap ini bertujuan untuk mengetahui masalah yang terjadi sehingga dapat diselesaikan pada penelitian ini.

\section{Tahap Perancangan( Desain)}

Tahap perancangan yang mana dilakukan tahap pembuatan media yang akan digunakan dalam pembejaran. Perancangan media berupa permainan monopoli yang dihadirkan dalam bentuk prototype.Tahapan ini dilakukan dalam 2 tahap yaitu pemilihan media yang penggunaannya dengan metode STAD (Student Team Achievement Division) dan pemilihan format media.Pengembangan media ini dalam pelaksanaannya menggunakan metode STAD yang mana langkah-langkahnya: a.Penyampaian tujuan dan motivasi, b.Pembagian kelompok, c.Persentasi dari guru, d. Kegiatan belajar dalam tim atau kerja tim, d. kuis atau evluasi dan f.Penghargaan tim.

\section{Tahap Pengembangan (Develop)}

Tahap pengembangan ini untuk menghasilkan produk pengembangan media yang telah direvisi dengan saran oleh beberapa validator yang dilakukan dengan validasi ahli media.Validasi yang dilakukan oleh beberapa ahli ini meliputi ahli materi dan ahli desain media.

\section{Tahap Penyebaran (Disseminate)}

Penelitian pengembangan dibatasi sampai tahap disseminate (penyebaran). Penelitian ini pada tahap penyebaran tidak dilakukan karena masalah biaya, waktu dan tenaga. Pengembangan sudah melewati pendefinisian, perancangan dan pengembangan dirasa sudah mencukupi untuk meningkatkan pemahaman siswa dengan menggunakan pengembangan media pembelajaran biologi berupa permainan monopoli materi sistem pencernaan berbasis metode STAD.

Subjek coba dalam penelitian ini divalidasi oleh dua dosen Universitas Muhammadiyah Metro sebagai ahli media, dua dosen yang berkompeten pada aspek materi sistem pencernaan manusia,dan guru mata pelajaran biologi SMA $\mathrm{N} 1$ Punggur lalu diujicobakan ke peserta didik kelas XI di SMA N 1 Punggur. Tahap analisis data ini yaitu mengolah data yang telah diperoleh oleh peneliti. Pengumpulan data bertujuan untuk menghitungpresentase kelayakan dan keterbacaannya sesuai dengan pernyataan yang telah diberikan, dalam perhitungan ini, menggunakan rumus sebagai berikut:

$$
\text { Nilai }=\frac{\text { Rata }- \text { Rata Skor Validasi }}{\text { Jumlah Skor Maksimal }}
$$

Sumber: Herdianawati (2013)

Menafsirkan persentase angket untuk mengetahui kelayakan media secara keseluruhan dapat dilihat dalam Tabel 1. 
Tabel 1. Kriteria Persentase Skor Penilaian

\begin{tabular}{|l|l|l|}
\hline Persentase & Kriteria & Ket. \\
\hline $85 \%-100 \%$ & $\begin{array}{l}\text { Sangat } \\
\text { Baik }\end{array}$ & $\begin{array}{l}\text { Tidak } \\
\text { Perlu } \\
\text { Direvisi }\end{array}$ \\
\hline $75 \%-84 \%$ & Baik & $\begin{array}{l}\text { Tidak } \\
\text { Perlu } \\
\text { Direvisi }\end{array}$ \\
\hline $65 \%-74 \%$ & $\begin{array}{l}\text { Cukup } \\
\text { Baik }\end{array}$ & $\begin{array}{l}\text { Perlu } \\
\text { Direvisi }\end{array}$ \\
\hline $55 \%-64 \%$ & $\begin{array}{l}\text { Kurang } \\
\text { Baik }\end{array}$ & $\begin{array}{l}\text { Perlu } \\
\text { Direvisi }\end{array}$ \\
\hline $0 \%-54 \%$ & $\begin{array}{l}\text { Sangat } \\
\text { Kurang } \\
\text { Baik }\end{array}$ & $\begin{array}{l}\text { Perlu } \\
\text { Direvisi }\end{array}$ \\
\hline
\end{tabular}

Sumber : Ramlan (2013)

Penelitian ini dikatakan berhasil jika hasil dari setiap instrumen yang didapat menunjukkan persentase $\geq 75$ atau pada kriteria "baik" sampai pada kriteria "sangat baik". Hal ini menjelaskan bahwa media pembelajaran yang dikembangkan dan dibuat peneliti sudah layak dan baik untuk digunakan dalam proses pembelajaran peserta didik.

\section{HASIL}

Hasil dari analisis data menunjukkan kriteria persentase kelayakan "Baik" dan "Sangat baik", Media tersebut dalam proses pembelajaran, guna menciptakan media yang efektif, memiliki daya tarik dan dapat menjadi perantara interaksi baik antar peserta didik maupun dengan guru. Pengujian media dilakukan dengan 2 cara yaitu angket kepada ahli media pembelajaran dan juga ahli materi pembelajaran yang masing-masing 2 dosen serta angket uji respon siswa ke sekolah sebanyak 20 orang. Angket yang telah divalidasi oleh beberapa ahli memiliki hasil yang berbeda-beda.Analisis data digunakan untuk mengetahui kelayakan media sebagai sarana pembelajaran biologi materi sistem pencernaan kelas XI SMA $\mathrm{N} 1$ Punggur.Hasil rekapitulasi data hasil uji ahli dan respon siswa dapat dilihat pada data hasil validasi uji ahli dan uji respon siswa.

\section{Analisis Data}

Berdasarkan hasil analisis data yang diperoleh dari penilain para ahli yang diperolehdiimplementasikan dalam kriteria kelayakan menurut Ramlan (2013) maka nilai dari ahli desain media, ahli materi, guru dan peserta didik dengan kriteria "Sangat Baik".Validasi dosen sebagai ahli desain media mencapai skor $86,6 \%$ dengan kriteria "Sangat Baik", validasi dosen sebagai ahli materi pembelajaran mencapai skor $90,8 \%$ dengan kriteria "Sangat Baik", validasi guru mata pelajaran sebagai ahli aspek desain media mencapai skor $90,8 \%$ dengan kriteria " Sangat Baik" dan sebagai ahli materi mencapai skor $87,5 \%$ dengan kriteria "Sangat Baik", penilaian produk dari uji coba peserta didik (Uji Kelompok Kecil) mencapai skor 90,25\% dengan kriteria “ Sangat Baik".Hasil rekapitulasi validasi ahli dan uji coba peserta didik menunjukkan kriteria sangat baik yaitu: (a) Aspek desain media mencapai rata-rata skor $88,7 \%$ (b) Aspek materi mencapai rata-rata skor $89,1 \%$ dan (c) uji coba peserta didik mencapai skor $90,25 \%$.

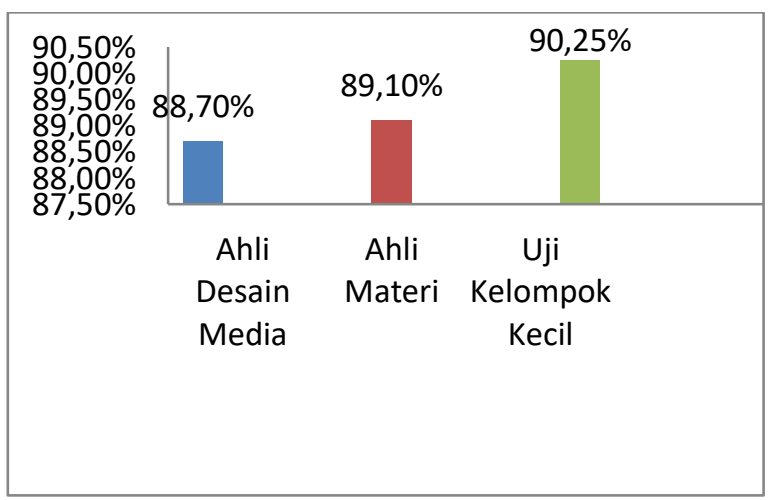

Gambar 5. Hasil Analisis Data

Hasil yang telah didapat memasuki range $88 \%-100 \%$ dengan nilai rata-rata sebesar 91\% dengan kriteria "Sangat Baik".

2. Revisi Produk

Tabel 15. Saran dan Masukan Produk Media oleh Ahli 
RAHAYU, I. S., SANTOSO, H., ASIH, T. 2019. Permainan Monopoli...

\begin{tabular}{|c|c|c|}
\hline No & Ahli & $\begin{array}{l}\text { Saran dan } \\
\text { Masukan }\end{array}$ \\
\hline 1. & $\begin{array}{l}\text { Ahli } \\
\text { Media }\end{array}$ & $\begin{array}{l}\text { 1. Ukuran kartu } \\
\text { soal disesuaikan } \\
\text { dengan media } \\
\text { 2. Tulisan pada } \\
\text { lembar } \\
\text { monopoli tips } \\
\text { untuk menjaga } \\
\text { kesehatan } \\
\text { dikontraskan } \\
\text { dengan warna } \\
\text { dasar media } \\
\text { 3. Tulisan } \\
\text { Universitas } \\
\text { Muham } \\
\text { madiyah Metro } \\
\text { dicover } \\
\text { dirapikan } \\
\text { 4. Panduan } \\
\text { Permainan } \\
\text { Monopoli } \\
\text { disederhanakan }\end{array}$ \\
\hline 2. & $\begin{array}{l}\text { Ahli } \\
\text { Materi }\end{array}$ & $\begin{array}{l}\text { 1. Daftar Pustaka } \\
\text { dilengkapi } \\
\text { 2. Penambahan } \\
\text { materi sesuai } \\
\text { KD } \\
\text { 3. Sesuaikan kartu } \\
\text { soal yang } \\
\text { diperiksa sesuai } \\
\text { KKO } \\
\text { 4. Penambahan } \\
\text { petunjuk yang } \\
\text { mewakili bahwa } \\
\text { adanya interaksi } \\
\text { guru dan peserta } \\
\text { didik }\end{array}$ \\
\hline 3 & $\begin{array}{l}\text { Guru } \\
\text { Mata } \\
\text { Pelaja } \\
\text { ran }\end{array}$ & $\begin{array}{l}\text { 1. Gambar pada } \\
\text { kartu soal } \\
\text { diperbaiki lagi }\end{array}$ \\
\hline 4 & $\begin{array}{l}\text { Pesert } \\
\text { a } \\
\text { Didik }\end{array}$ & $\begin{array}{l}\text { 1. Kurang adanya } \\
\text { tanda panah } \\
\text { pada kartu soal } \\
\text { nomor } 1\end{array}$ \\
\hline
\end{tabular}

PEMBAHASAN
Hasil produk media yang dikembangkan dalam penelitian ini yaitu produk Media Pembelajaran Biologi Berupa Permainan Monopoli materi Sistem Pencernaan Berbasis Metode STAD (Student Teams Achievement Division). Berdasarkan analisis data yang dilakukan oleh validator ahli desain media dan ahli materi yang telah dilakukan oleh 4 dosen Universitas Muhammadiyah Metro, juga guru mata pelajaran SMA N 1 Punggur yang memvalidasi angket dan memberikan masukan dari aspek media dan aspek materi dengan mengisi angket yang telah disediakan dengan melakukan berbagai revisi dan telah diujicobakan ke peserta didik sebanyak 20 orang responden. Produk hasil pengembangan mendapatkan persentase tingkat kelayakan media dari ahli media sebesar mencapai skor $86,6 \%$ dengan kriteria "Sangat Baik", validasi dari ahli materi mencapai skor $90,8 \%$ dengan kriteria "Sangat Baik". Guru mata pelajaran penilaian validasi untuk aspek media mencapai skor 90,8\% dengan kriteria "Sangat Baik" sedangkan pada aspek materi pembelajaran mencapai skor $87,5 \%$ dengan kriteria "Sangat Baik". Produk yang sudah divalidasi dan direvisi lalu diujicobakan ke peserta didik (uji kelompoK kecil) dan mendapat skor mencapai 90,25\% dengan kriteria "Sangat Baik" berdasarkan tafsir dari Ramlan (2013) sehingga dapat digunakan untuk pendukung proses pembelajaran.

Berdasarkan hasil validasi yang dilakukan oleh ahli desain media, materi, dan guru mata pelajaran dan sudah diujicobakan ke responden peserta didik maka media ini layak dan bermanfaat untuk media sarana dalam proses pembelajaran. Manfaat media sebagai proses pembelajaran sudah dijelaskan oleh Arsyad (2010:26) bahwa media bermanfaat untuk dapat memperjelas penyampaian pesan dan informasi sehingga dapat mempermudah dan meningkatkan proses pembelajaran dan hasil belajar, pembelajaran dapat meningkatkan dan mengarahkan perhatian peserta didik sehingga dapat menimbulkan 


\section{RAHAYU, I. S., SANTOSO, H., ASIH, T. 2019. Permainan Monopoli...}

motivasi dan semangat belajar, interaksi yang langsung antara siswa dan lingkungannya dan interaksi siswa dengan gurunya, media pembelajaran dapat memberikan kesamaan pengalaman kepada siswa tentang peristiwa yang terjadi di lingkungan mereka baik dengan guru maupun dengan lingkungannya. Media permainan monopoli ini setelah diujicobakan ke peserta didik memberikan manfaat bahwa dapat digunakan sebagai media penyampaian materi dalam proses pembelajaran.

Pengembangan media permainan monopoli menurut validasi yang diujicobakan ke peserta didik mereka merasa lebih aktif dalam belajar, tidak mengalami kebosanan sehingga dalam pemahaman materi lebih optimal seperti yang telah dijabarkan oleh fitriyawani (2013) menyatakan bahwa permainan monopoli ini merupakan media permainan yang dapat menimbulkan kegiatan pembelajaran yang menarik, santai namun serius juga menyenangkan serta mempunyai kemampuan untuk melibatkan siswa dalam kegiatan belajar mengajar secara aktif dan bebas untuk menyatakan pendapat mereka dalam pembelajaran.

Berdasarkan hasil validasi ahli materi bahwa pembelajaran yang disusun pada Media Permainan Monopoli Materi Sistem Pencernaan Berbasis Metode STAD menimbulkan adanya interaksi antara peserta didik dan guru mendapat skor mencapai $90 \%$ maka berkaitan dengan tafsiran Slavin dalam Rusman (2012:213) bahwa gagasan utama metode STAD adalah memacu peserta didik agar saling mendorong dan membantu satu sama lain untuk menguasai materi yang disampaikan yang diajarkan guru. Produk yang dikembangkan berupa media monopoli materi sistem pencernaan dengan menggunakan metode STAD dapat menimbulkan interaksi peserta didik dan guru maupun antar peserta didik yang lainnya. Pengembangan media berupa permainan monopoli berbasis metode STAD membantu peserta didik dalam memahami materi dan lebih semangat agar mempunyai motivasi yang tinggi untuk terus belajar karena langkah-langkahnya terdaat pengumpulan skor terbanyak maka akan keluar jadi pemenang yang akan mendapat penghargaan seperti yang dikemukakan oleh isjoni (2010) bahwa STAD merupakan salah satu tipe kooperatif yang menekankan pembelajaran pada adanya aktivitas dan interaksi diantara siswa untuk saling memotivasi dan saling membantu dalam menguasai materi pelajaran guna mencapai prestasi yang maksimal.

Pengembangan produk berupa media monopoli materi sistem pencernaan dengan Metode STAD terdapat kelebihan dan juga kelemahan media. Adapun kelebihan dan kelemahan produk sebagai berikut:

1. Kelebihan

a. Media Monopoli dapat meningkat motivasi belajar peserta didik.

b. Media pembelajarannya interaktif.

c. Media yang mudah digunakan dalam proses pembelajaran.

d. Media permainan monopoli yang mudah dibawa kemanamana.

e. Media pembelajaran memuat semua materi sistem pencernaan dan dilengkapi dengan soal.

f. Media dapat menimbulkan keaktifan peserta didik karena berupa permainan sehingga mereka tidak mengantuk saat pembelajaran.

g. Media Pembelajaran menghilangkan rasa bosan dan mengantuk saat belajar karena peserta didik diwajibkan menjawab pertanyaan.

h. Media yang isi materi tidak hanya kognitif saja namun aspek sosial juga tedapat pada media tersebut.

2. Kelemahan

a. Soal latihan pada media minim 
RAHAYU, I. S., SANTOSO, H., ASIH, T. 2019. Permainan Monopoli...

b. Media pembelajaran hanya di kembangkan pada materi Sistem Pencernaan Kelas XI

\section{KESIMPULAN}

Pengembangan

Permainan

Monopoli Sebagai Media Pembelajaran Biologi Materi Sistem Pencernaan Berbasis Metode STAD (Student Teams Achievement Division) sudah layak untuk sarana penyampaian pesan pada proses pembelajaran.

\section{SARAN}

Berdasarkan hasil pengembangan media pembelajaran biologi permainan monopoli materi sistem pencernaan berbasis metode STAD diharapkan media dapat dimanfaatkan oleh guru dan peserta didik untuk digunakan untuk pendukung proses pembelajaran. Pengembangan media dapat dimanfaatkan untuk khalayak masyarakat dengan mengunduh hasil pengembangan ke blog dan bisa dicetak kembali. Pengembangan media ini dapat dikembangkan dengan melanjutkan ke hasil pembelajaran dan juga bisa diganti dengan materi-materi yang lain. Produk media pembelajaran biologi berupa permainan monopoli dengan metode STAD juga memiliki manfaat untuk para penggunanya baik peserta didik, guru dan khalayak umum agar selalu menjaga kesehatan tubuh dengan menjaga pola makan dengan teratur dan usahakan makan tidak terlambat sehingga dapat mengganggu proses pencernaan itu sendiri.Produk yang dikembangkan dapat digunakan oleh guru, peserta didik dan khalayak umum dalam proses pembelajaran. Produk yang telah dikembangkan ini bisa dilakukan penelitian hingga sampai hasil belajar oleh peneliti.Materi pada produk bisa diganti dengan materi yang lainnya.

\section{DAFTAR PUSTAKA}

Arsyad, Adzar. 2010.Media
Pembelajaran. Bandung. PT
Rajagrafindo Persada.

Astuti. 2014. Pengembangan Media Pembelajaran Monopoli Menggunakan Xampp Untuk Pembelajaran Apresiasi Cerpen Siswa Kelas VII SMP Negeri 2 Jember. Nosi Volume 2 Nomor 4 Agustus2014.Magister Pendidikan Bahasa Indonesia.

Duludu, Ummysalam. 2017. Kurikulum Bahan dan Media Pembelajaran PLS.Yogyakarta:CV Budi Utomo.

Fitriyawani, (2013). Penggunaan Media

Permainan Monopoli Melalui Pembelajaran Kooperatif.Jurnal Ilmiah DIDAKTIKA, 13 (2), 223239. Mahasiswa Fisika Fakultas Tarbiyah dengan Konsep Tata Surya.

Herdianawati,Nur Eka Kusuma dan Trisna Amelia.2018. Pengembangan

Lembar Kegiatan Siswa Inkuiri Berbasis Berfikir Kritis Pada Materi Daur Biogeokimia Kelas X.Jurnal Biedu.Vol 02 No 01 Januari.Universitas Negeri Surabaya.

Ramlan, Haerudin dan Kamaludin. 2013. Pengembangan Media

Pembelajaran E-Materi Dengan Model Pembelajaran Berbasis Masalah Pada Materi Suhu dan Kalor. Jurnal Pendidikan Fisika Tadulako (JPFT) Vol 1 No 2. Universitas Tadulako.

Rusman. 2014. Model-Model Pembelajaran. Depok: PT Rajagrafindo Persada.

Taufiq, Moh. 2015. Pemanfaatan Model Pembelajaran Tipe STAD Dapat Menigkatkan Prestasi Belajar IPABiologi Tentang Ekskresi Pada Manusia. Journal Saintifika, ISSN : 1411-5433 Volume 17, Nomor 1 Juni 2015.SMP Negeri 8 Kota Pasuruan, Indonesia. 